\title{
Liquiritin induces apoptosis and autophagy in cisplatin (DDP)-resistant gastric cancer cells in vitro and xenograft nude mice in vivo
}

\author{
FENG WEI $^{1}$, XIN JIANG $^{3}$, HAO-YUE GAO $^{4}$ and SHUO-HUI GAO ${ }^{2}$ \\ ${ }^{1}$ Department of Hepatobiliary and Pancreas Surgery, First Hospital of Jilin University; \\ ${ }^{2}$ Department of Gastrointestinal Colorectal Surgery, China-Japan Union Hospital of Jilin University; \\ ${ }^{3}$ Department of Biochemistry, Basic College of Medicine, Jilin University; \\ ${ }^{4}$ Basic College of Medicine, Jilin University, Changchun, Jilin 130021, P.R. China
}

Received May 26, 2017; Accepted July 20, 2017

DOI: 10.3892/ijo.2017.4134

\begin{abstract}
Gastric cancer is reported as one of the leading factors resulting in tumor-related death worldwide. However, the therapies to suppress gastric cancer are still limited and the emergence of drug resistance makes it necessary to develop new and effective anticancer drugs and combinational chemotherapy schemes. Liquiritin (LIQ) is a major constituent of Glycyrrhiza Radix, exhibiting various pharmacological activities, including anticancer. In this study, we investigated the role of LIQ in human gastric cancer cells with cisplatin (DDP) resistance. The findings suggested that LIQ, when applied in single therapy, could moderately inhibit the proliferation and migration of DDP-resistant gastric cancer cells, SGC7901/DDP. DDP and LIQ in combination induced G0/G1 cell cycle arrest to suppress the proliferation of gastric cancer cells, which were associated with the decrease of cyclin D1, cyclin A and cyclin-dependent kinase 4 (CDK4) and increase of p53 and p21. In addition, LIQ combined with DDP significantly induce apoptosis and autophagy both in vitro and in vivo through enhancing cleavage of caspase-8/-9/-3 and PARP, as well as LC3B and Beclin 1 expression. Significantly, the two drugs, when used in combination, prevented gastric cancer cell xenografts in nude mice in vivo. Together, the results revealed that application of DDP and LIQ in combination possessed a potential value against the growth of human gastric cancer with DDP resistance.
\end{abstract}

Correspondence to: Dr Feng Wei, Department of Hepatobiliary and Pancreas Surgery, First Hospital of Jilin University, Changchun, Jilin 130021, P.R. China

E-mail: 2086842887@qq.com

Professor Shuo-Hui Gao, Department of Gastrointestinal Colorectal Surgery, China-Japan Union Hospital of Jilin University, 126 XianTai Street, Changchun, Jilin 130021, P.R. China

E-mail: gaoshuohui@foxmail.com

Key words: gastric cancer, liquiritin, DDP resistance, apoptosis, autophagy

\section{Introduction}

Gastric cancer is one of the most common types of cancer, currently, and it remains a worldwide burden as the second leading cause of cancer-associated death, whereas the incidence rate is gradually rising every year in the world $(1,2)$. Though a variety of advances, such as surgery, have been achieved to inhibit gastric cancer progression in recent years, the therapeutic effect is still far from satisfactory (3). Furthermore, various chemical drugs are suggested as the first-line therapy. However, side effects are observed due to cytotoxicity (4). In addition, the drug resistance to chemotherapeutics develops in gastric cancer cells, resulting in tumor recurrence and even further progression $(5,6)$. Therefore, the drug resistance of chemotherapy is considered as a major clinical obstacle to successful treatment, and new chemotherapeutics, including drugs in combination, used against human gastric cancer are still needed (7). Cisplatin (DDP)-based chemotherapy is reported as the main strategy to prevent human gastric cancer. However, drug resistance is also a major obstruction for DDP chemotherapy $(8,9)$.

Licorice, known as medicinal plant in China, Korea and Japan, has a variety of pharmacological activities, including antibacterial, anti-inflammatory and antioxidant activities, and even anticancer ability $(10,11)$. Liquiritin (LIQ) is a main component among the licorice flavonoids, and has also been suggested to possess anti-inflammatory and anticancer abilities $(12,13)$. However, its effects, as well as its combination with DDP, have not been well investigated on the regulation of human gastric cancer with drug resistance.

In the present study, for the first the synergistic effect of LIQ on DDP-induced apoptosis and autophagy was evaluated in human gastric cancer SGC-7901/DDP cells. Our results indicated that LIQ enhanced the sensitivity of SGC-7901/DDP cells to DDP treatment through inducing G0/G1 cell cycle arrest, increasing the pro-apoptosis via upregulating the cleaved caspase-8/-9/-3 and PARP, and inducing autophagy by improving LC $3 \mathrm{~B}$ and Beclin 1 expression. In vivo, LIQ enhanced the suppressive effects of 
DDP on tumor growth in SGC-7901/DDP xenograft model. Our results suggested that LIQ might serve as a synergistic drug with chemotherapeutic drugs DDP in the prevention of gastric cancer.

\section{Materials and methods}

Cells and culture. The drug (DDP)-resistant SGC7901/DDP cells were purchased from the KeyGen Biotech Development Co., Ltd. (Nanjing, China). The cells were grown in RPMI-1640 medium containing $10 \%(\mathrm{v} / \mathrm{v})$ fetal calf serum (Gibco, USA), $100 \mathrm{U} / \mathrm{ml}$ penicillin, and $100 \mu \mathrm{g} / \mathrm{ml}$ streptomycin. All cells were then incubated in a $37^{\circ} \mathrm{C}$ incubator with $5 \% \mathrm{CO}_{2}$. SGC7901/DDP cells were routinely maintained in the above RPMI-1640 medium containing $10 \mu \mathrm{g} / \mathrm{ml}$ cisplatin (Sigma-Aldrich Chemical Co., USA). Lquiritin (purity, HPLC $\geq 98 \%$ ) was obtained from Xi'an Jing Cheng Biological Technology Co., Ltd. (Xi'an, China).

Cell death analysis.3-(4,5-dimethyl-2-thiazolyl)-2,5-diphenyl2-H-tetrazolium bromide (MTT) (Beyotime, Nanjing, China) was used to calculate cell viability. Cells $\left(2 \times 10^{3}\right) /$ well were seeded on 96-well plates and treated under different conditions as indicated and incubated at $37^{\circ} \mathrm{C}(14,15)$. MTT solution (300 $\mu 1 /$ well) was added after incubation. Following incubation at $37^{\circ} \mathrm{C}$ for an additional $4 \mathrm{~h}$, the supernatants were removed and $200 \mu \mathrm{l}$ dimethyl sulfoxide (DMSO, Sigma-Aldrich) was added into each well to dissolve the formazan crystals. The 96-well plates were then placed in a microplate reader to determine the absorbance at $490 \mathrm{~nm}$. Each test was carried out in triplicate.

Migration assays. SGC7901/DDP cells (1x10 $)$ after incubation with DPP, LIQ or the co-treatment of the two drugs for $24 \mathrm{~h}$ were seeded into the upper chamber of a Transwell ${ }^{\circledR}$ system (Corning, USA) following the manufacturer's instructions. The medium in the lower chamber contained 5\% FBS as a source of chemoattractants. Cancer cells were suspended in serum-free medium. The cultures were rinsed with PBS and the medium was replaced with fresh medium alone or supplemented with $10 \% \mathrm{FBS}$. The cells were then incubated for $24 \mathrm{~h}$ at $37^{\circ} \mathrm{C}$. The number of cells in migration was counted under a microscope.

Colony formation analysis. SGC7901/DDP cells $\left(1 \times 10^{4}\right)$ were first incubated with DPP, LIQ or the two in combination for $24 \mathrm{~h}$. Also, then the medium was removed and the cells were seeded into the upper chamber of Transwell systems (Corning) in accordance with the manufacturer's instructions. The medium in the lower chamber was supplemented with $5 \%$ fetal bovine serum (FBS, Gibco) as a source of chemoattractants. SGC7901/DDP cells were then suspended in serum-free medium. The cultures were washed with PBS and the medium was replaced with fresh medium alone or supplemented with 5\% FBS. Next, SGC7901/DDP cells were incubated for another $24 \mathrm{~h}$ at $37^{\circ} \mathrm{C}$. The number of migrated cells was counted with a microscope.

The wound healing analysis. SGC7901/DDP cells were seeded and grown on a 6-well plate treated with DPP, LIQ or the two in combination for $24 \mathrm{~h}$. Then, the monolayers of cancer cells were wounded using a pipette tip. Gastric cancer cells were then rinsed with PBS to remove cellular debris and subjected to migration for $24 \mathrm{~h}$. The representative images were captured on 0 and $24 \mathrm{~h}$, respectively, after the wound using an inverted microscope.

Cell cycle arrest analysis. The effect of LIQ, DDP or LIQ/DDP co-treatment on cell cycle distribution was examined using flow cytometry analysis. After treatment under various conditions, all cells were harvested and fixed in 70\% ethanol. The cells were then washed with PBS twice and stained with PI solution containing $50 \mu \mathrm{g} / \mathrm{ml}$ PI and $25 \mu \mathrm{g} / \mathrm{ml}$ RNAse for $30 \mathrm{~min}$. Finally, all cells were analyzed by a FACSCalibur flow cytometer (BD Pharmingen, USA).

Assessment of apoptosis. SGC7901/DDP cells treated under different conditions as indicated were harvested in PBS. Then, the cells were incubated with Annexin V-FITC and PI (Sigma-Aldrich) for $15 \mathrm{~min}$ in a darkroom at room temperature. Then, the stained cells were analyzed through flow cytometry (BD Pharmingen).

Hoechst 33258 staining of SGC7901/DDP cells was used to determine the apoptotic status. Cells $\left(1 \times 10^{6}\right) / \mathrm{ml} \mathrm{SGC7901/}$ DDP cells were seeded in 6-well plates and then treated as indicated. The cells were collected after various treatments, washed with PBS twice, and fixed with 4\% paraformaldehyde (Taize Ruida Technology Co. Ltd., Beijing, China) for $10 \mathrm{~min}$ and then washed with PBS three times. Next, the cells were stained with Hoechst 33258 solution (Beyotime) following the manufacturer's instructions. The representative images were immediately captured through a fluorescence microscope (Olympus Corp., Japan) to calculate the apoptotic cells.

SGC7901/DDP cells were exposed to LIQ, DDP or the two in combination for $24 \mathrm{~h}$ on 12 -well plates. Next, the One Step TUNEL Apoptosis assay kit (KeyGen Biotech) was used to determine the apoptosis following the manufacturer's instructions. The staining intensity was assessed through a fluorescence microscopy.

Mitochondrial potential evaluation. JC-1 and JC-10 dye loading solutions (Abcam, USA) were added to SGC7901/ DDP cells after various treatments as described and incubated for $30 \mathrm{~min}$. The fluorescent intensities for both J-aggregates and monomeric forms of JC- 1 and JC-10 were calculated at $\mathrm{Ex} / \mathrm{Em}=490 / 525 \mathrm{~nm}$ and $490 / 590 \mathrm{~nm}$ using a microplate reader.

Measurement of caspase activity. Caspase activity kits (Beyotime Biotech) were used to assess caspase activity according to the manufacturer's instructions. SGC7901/DDP cells underwent various treatments, then the lysates were prepared. Activities of caspase-8/-9 and -3 was measured by the use of substrate peptides Ac-IETD-pNA, Ac-LEHD-pNA and Ac-DEVD-pNA, respectively. Also, the pNA release was determined by calculating the absorbance at $405 \mathrm{~nm}$ using a microplate reader.

Transmission electron microscopy (TEM) assays. After different treatments as indicated, SGC7901/DDP cells were collected and washed with PBS and then fixed in glutaralde- 
hyde $(2.5 \%)$ overnight. The cells were washed by PBS (0.1 M) and fixed with $\mathrm{OsO}_{4}(1 \%)$. Next, the SGC7901/DDP cells were dehydrated with a range of alcohol concentrations for $15 \mathrm{~min}$. The cells were then embedded into paraffin and sliced using an LKB-V ultramicrotome (LKB, Bromma, Sweden). For acquiring TEM images, the prepared sections were observed on a JEM-2100 microscope operating at an accelerating voltage of $200 \mathrm{kV}$ (Jeol Ltd., Tokyo, Japan).

Western blot analysis. SGC7901/DDP cells after different treatments were harvested and washed with chilled PBS. The cells and gastric tumor tissues were lysed in $50 \mathrm{mM}$ Tris- $\mathrm{Cl}$ (pH 7.5) containing $150 \mathrm{mM} \mathrm{NaCl}, 0.5 \%$ deoxycholic acid, $1 \%$ NP-40, $0.1 \%$ SDS, and a protease inhibitor (Sigma-Aldrich) on ice for $10 \mathrm{~min}$ to yield a homogenate. The final supernatants were obtained by centrifugation at $15,000 \mathrm{x} g$ for $15 \mathrm{~min}$ at $4^{\circ} \mathrm{C}$. The concentration of protein was measured using BCA protein assay kit (Thermo Fisher Scientific, USA) with bovine serum albumin as a standard. Sample-loading buffer was added, the mixture was boiled for $5 \mathrm{~min}$. The total protein extract are used for western blot analysis. Total protein (40 $\mu \mathrm{g}$ ) was loaded and the proteins were then separated using 10\% SDS-PAGE and electrophoretically transferred to the polyvinylidene difluoride membranes (Millipore, USA). Then, the membranes were blocked with skim milk $(5 \%)$ Tris-buffered saline with $0.1 \%$ Tween-20 (TBST), washed, and then incubated with primary antibody overnight at $4^{\circ} \mathrm{C}$. The membrane was then washed with TBST three times, followed by incubation with a horseradish peroxidase (HRP)conjugated secondary antibody (Santa Cruz Biotechnology Inc., USA) at room temperature for $2 \mathrm{~h}$. Following another round of washing with TBST, the membrane was then developed using ECL, and exposed to Kodak (Eastman Kodak Co., USA) X-ray film. The protein expression levels were defined as grey value by the use of ImageJ 1.38 software (National Institutes of Health, USA) and standardized to housekeeping gene of GAPDH and expressed as a fold of control. All experiments were performed in triplicate independently. The primary antibodies for GAPDH (1:1,000, ab8245, Abcam), p53 (1:1,000, ab1431, Abcam), p62 (1:1,000, ab56416, Abcam), Beclin 1 (1:1,000, ab62557, Abcam), LC3B (1:1,000, ab48394, Abcam), caspase-8 (1:1,000, ab25901, Abcam), caspase-9 (1:1,000, ab25758, Abcam), cyclin A $(1: 1,000,4656$, Cell Signaling Technology, USA), cyclin D1 (1:1,000, 2978, Cell Signaling Technology), CDK4 (1:1000, ab137675, Abcam), p21 (1:500, KD1406, Santa Cruz Biotechnology), caspase-3 (1:1,000, ab52293, Abcam), and PARP (1:1,000, ab4830, Abcam) were included.

Animals and treatments. Forty, 5-week-old male BALB/c-nu mice, weighed 15-18 g, were subcutaneously injected with $2 \times 10^{5}$ SGC7901/DDP cells in the left flank. All mice were purchased from Shanghai Laboratory Animal Center (Shanghai, China). Before the experiments, the mice were acclimatized to the new environment for a week. All protocols used followed the Regulations of Experimental Animal Administration issued by the Ministry of Science and Technology of the People's Republic of China. Mouse care and usage were performed in accordance with the ethical guidelines of Huai'an First People's Hospital, Nanjing Medical
University (Nanjing, China). The mice were raised in airconditioned pathogen-free rooms at $25 \pm 2^{\circ} \mathrm{C}$ with $50 \pm 10 \%$ humidity under controlled lighting (12 h light/day) and fed with standard laboratory food and water. When the tumors were visible (the tumor size reached to $50 \mathrm{~mm}^{3}$ ), the mice were randomly divided into four groups (10 mice per group). The control group received the vehicle (PBS) injection i.p., and the treatment group was administered with LIQ (15 mg/kg), DDP $(3 \mathrm{mg} / \mathrm{kg}$ ) and the two in combination i.p. every day $(16,17)$. Liquiritin was dissolved in PBS, and it was dispersed in PBS to form an aqueous suspension in ultrasonic water bath for i.p. injection. After treatments for 21 days, all animals were sacrificed. The tumors were excised and measured. Also, the tumor tissues were fixed in $10 \%$ formalin for further research.

The immunohistochemical analysis. Formalin-fixed tumor tissue samples were first embedded in paraffin (4\%) and then the paraffin-embedded samples were cut into serial sections (3 $\mu \mathrm{m}$ thickness). Primary tumor sections were stained with hematoxylin and eosin (H\&E). Mouse gastric tumors were sectioned (3 $\mu \mathrm{M}$ thickness), and stained with Ki-67 (Abcam), and analyzed through a microscope. The representative images were arranged using TissueFAXs (Tissue-Gnostics) software. The percentage of Ki-67-positive cells in each tumor section was quantified. The apoptosis of tumor tissues was also measured via TUNEL assay using a In situ Apoptosis Detection kit (KeyGen Biotech) in line with the manufacturer's protocol. After deparaffinization and hydration, tumor tissue sections were rinsed with PBS for twice and then incubated with proteinase $\mathrm{K}(20 \mu \mathrm{g} / \mathrm{ml}$, Abcam $)$ at $37^{\circ} \mathrm{C}$ for $25 \mathrm{~min}$, which was followed by washing with PBS. Next, all sections were incubated with TUNEL mixture. The gastric tumor sections were counter-stained with DAPI. In the end, the tissue sections were observed with a microscope. In addition, for immunohistochemical analysis of cleaved caspase- 3 and LC3B, tumor tissue sections were deparaffinized in xylene, followed by hydration through graded alcohol, and treated with $3 \% \mathrm{H}_{2} \mathrm{O}_{2}$ for $15 \mathrm{~min}$. The boiling sodium citrate buffer was used for antigen retrieval for $10 \mathrm{~min}$. Next, tumor tissue sections were incubated with $10 \%$ normal goat serum for $15 \mathrm{~min}$, and then incubated with primary antibodies of active caspase- 3 and LC3B at $4^{\circ} \mathrm{C}$ overnight. Next, the slides were rinsed with PBS three times, the sections were incubated using secondary antibody for $30 \mathrm{~min}$ at $37^{\circ}$ C. 3,3'-diaminobenzidine (DAB, KeyGen Biotech) was used for the staining of the nucleus. Also, hematoxylin (Beyotime) was added for the counterstaining of the background.

Statistical assays. The quantitative data are presented as the mean \pm SEM of triplicate experiments. Statistically significant values were compared using the ANOVA and the Dunnett's post hoc test, and $\mathrm{p}<0.05$ was considered to indicate a statistically significant result.

\section{Results}

Liquiritin potentiates the suppressive effects of DDP on the proliferation of DDP-resistant gastric cancer cells. DDP-resistant gastric cancer cells (SGC7901/DDP) were treated with LIQ to explore if it could potentiate the effects of DDP on the suppression of gastric cancer progression. 

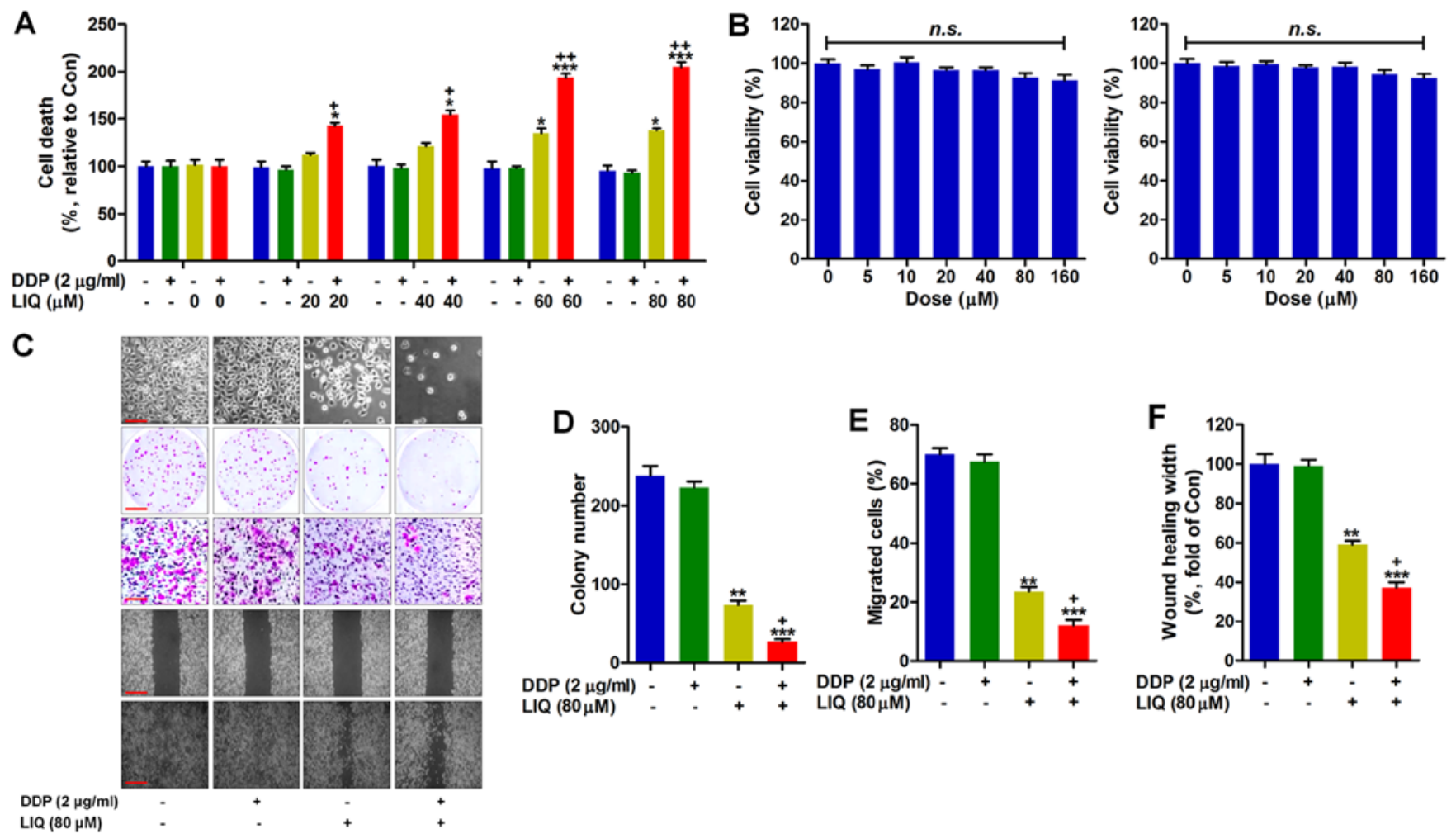

Figure 1. Liquiritin potentiates the suppressive effects of DDP on the proliferation of DDP-resistant gastric cancer cells. (A) SGC7901 cells were treated with $\operatorname{DDP}(2 \mu \mathrm{g} / \mathrm{ml})$ and LIQ $(0,20,40,60$ and $80 \mu \mathrm{M})$ or the two in combination as indicated for $24 \mathrm{~h}$. Then, the cell viability was calculated using MTT analysis. (B) The rat gastric mucosal cells (RGM-1, left) and human gastric epithelium cells (GES-1, right) were cultured with different concentrations (0, 5, 10, 20, 40, 80 and $160 \mu \mathrm{M}$ ) of LIQ for $24 \mathrm{~h}$, followed by MTT analysis to calculate the cell viability. (C) SGC7901/DDP cells were treated as indicated for $24 \mathrm{~h}$. Then, the morphology of cells was observed under a microscope. The colony formation was analyzed. The migration of cancer cells was determined; and the wound healing assay was carried out to further evaluate the migration of DDP-resistant gastric cancer cells treated by LIQ. (D) The number of clonogenetic cells was quantified. (E) The percentage of migrated cells is shown. (F) The relative wound healing width was quantified. Data are presented as the mean \pm SEM, ${ }^{*} \mathrm{p}<0.05,{ }^{* *} \mathrm{p}<0.01$ and ${ }^{* * *} \mathrm{p}<0.001$ versus the DDP-/LIQ group. ${ }^{+} \mathrm{p}<0.05,{ }^{++} \mathrm{p}<0.01$ and ${ }^{++} \mathrm{p}<0.001$ versus the DDP $/ \mathrm{LIQ}^{+}$group.

SGC7901 cells were cultured with DDP $(2 \mu \mathrm{g} / \mathrm{ml})$ and LIQ $(0,20,40,60$ and $80 \mu \mathrm{M})$ or the two in combination as indicated for $24 \mathrm{~h}$. Then, the cell death condition was investigated using MTT analysis. As shown in Fig. 1A, we found that treatment of DDP showed no influence on the cell death compared to the control group in the absence of DDP and LIQ (DDP-/LIQ-). LIQ single treatment was found to significantly increase the percentage of cell death. Of note, co-treatment of DDP and LIQ further elevated the cell death levels, which was comparable to the $\mathrm{DDP}^{-} / \mathrm{LIQ}^{+}$group. Also, LIQ-induced cell death was dose-dependent. Next, the potential cytotoxicity of LIQ was measured. The rat gastric mucosal cells (RGM-1, left) and human gastric epithelium cells (GES-1, right) were cultured with different concentrations $(0,5,10,20,40,80$ and $160 \mu \mathrm{M}$ ) of LIQ for $24 \mathrm{~h}$, followed by MTT analysis. As shown in Fig. 1B, the data indicated that there was no significant difference between the control group and the LIQ-treated groups. Thus, LIQ showed no cytotoxicity to normal gastric cells treated within our conditions, demonstrating its safety for application. Following, the morphology of SGC7901/DDP cells treated with DDP, LIQ or the two in combination was observed under a microscope. DDP and LIQ co-treatment showed stronger suppressive role in the proliferation of SGC7901/ DDP cells. Also, clonogenic analysis further confirmed the effective role of DDP/LIQ in suppressing the gastric cancer cells. In addition, the migration and wound healing analysis indicated that DDP/LIQ combination could markedly inhibit the migration of SGC7901/DDP cells in comparison to the $\mathrm{DDP}^{-} / \mathrm{LIQ}^{+}$group (Fig. 1C-F). In conclusion, LIQ was able to remarkably increase the sensitivity of SGC7901/DDP cells to DDP, contributing to the cell death.

\section{Liquiritin induces G0/G1 cell cycle arrest in DPP-resistant gastric cancer cells. Cell proliferation has a close relationship with the distribution of cell cycle phase. Thus, in order to verify if the growth suppression caused by DDP/LIQ was related to cell cycle arrest, the role of DDP/LIQ in the cell cycle distribu- tion was measured using flow cytometry. As shown in Fig. 2A and B, the proportion of SGC7901/DDP cells at G1/S was significantly increased after DDP/LIQ co-treatment compared to the LIQ-single treatment. Next, the cell cycle-associated molecules were calculated through western blot analysis. The results indicated that DDP and LIQ in combination markedly reduced cyclin D1, cyclin A and CDK4 expressions, while p53 and $\mathrm{p} 21$ were found to be enhanced, which were comparable to the single treatment of LIQ (Fig. 2C and D). Taken together, the findings above indicated that DDP/LIQ induced G0/G1 cell cycle arrest through modulating the important signals regarding to DNA damage.}

Liquiritin and DDP co-treatment enhances apoptosis in DDP-resistant gastric cancer cells through promoting 


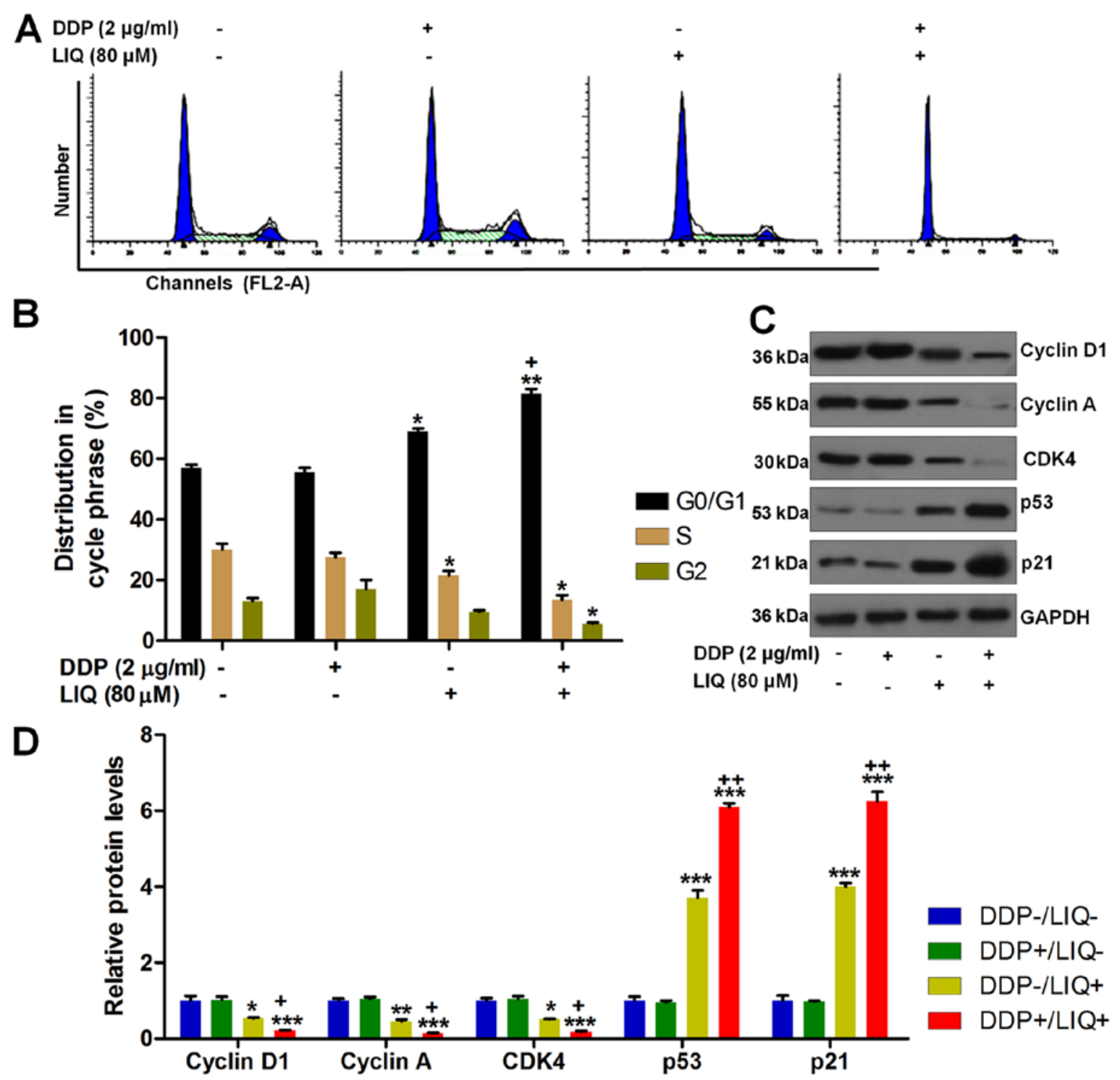

Figure 2. Liquiritin induces G0/G1 cell cycle arrest in DPP-resistant gastric cancer cells. (A) SGC7901/DDP cells were treated with DDP and LIQ or the two in combination for $24 \mathrm{~h}$, followed by flow cytometry to evaluate the distribution of cell cycle phrase. (B) The results of distribution in cycle phrase were exhibited following flow cytometry. (C) Western blot analysis was used to measure DNA damage checkpoint-related signals, including cyclin D1, cyclin A, CDK4, p53 and $\mathrm{p} 21$. (D) The relative quantification of each protein is displayed. Data are represented as the mean $\pm \mathrm{SEM},{ }^{*} \mathrm{p}<0.05,{ }^{* *} \mathrm{p}<0.01$ and ${ }^{* * *} \mathrm{p}<0.001$ versus the $\mathrm{DDP}^{-} / \mathrm{LIQ}^{-}$group. ${ }^{+} \mathrm{p}<0.05,{ }^{++} \mathrm{p}<0.01$ and ${ }^{+++} \mathrm{p}<0.001$ versus the $\mathrm{DDP} / \mathrm{LIQ}^{+}$group.

caspase-3 expression. Apoptosis plays an essential role in inducing cell death, which is widely used as a vital molecular mechanism to explore new and effective therapies against the progression of various tumors $(18,19)$. Fig. 3A illustrates that LIQ could effectively induce apoptosis in SGC7901/DDP cells, and considerably, LIQ combined with DDP further improved the apoptotic proportion. Similarly, Hoechst 33258 staining and TUNEL staining suggested that co-treatment of DDP and LIQ could dramatically induce apoptosis in SGC7901/DDP cells compared to the LIQ group (Fig. 3B). Further, the fluorescent intensities for both $\mathrm{J}$-aggregates and monomeric forms of JC-1 and JC-10 were markedly enhanced by DDP/LIQ co-treatment in SGC7901/DDP cells, which further proved that apoptosis was induced in DDP-resistant gastric cancer cells (Fig. 3C and D). Together, the results above indicated that DDP/LIQ could induce apoptosis in SGC7901/DDP cells, contributing to cell death.
Caspases are important signals involved in apoptosis induction (20). Thus, here we attempted to explore how these signals altered in SGC7901/DDP cells after various treatments. From Fig. 4A, we found that cleaved caspase-8/-9/-3 and PARP were highly induced by LIQ, and of note, DDP and LIQ in combination showed stronger effects to induce the expression of these proteins. Moreover, the activity of caspase-8/-9 and -3 in DDP-resistant gastric cancer cells was measured. As shown in Fig. 4B, DDP/LIQ co-treatment considerably enhanced caspase-8/-9 and -3 activiy, respectively, indicating that LIQ/DDP-induced apoptosis was tightly associated with caspase-3 pathway in SGC7901/DDP cells.

Liquiritin and DDP double therapy triggers autophagy in $D D P$-resistant gastric cancer cells. Autophagy is another molecular mechanism by which the cells are induced to death. Thus, autophagy plays an essential role in drug exploration for 

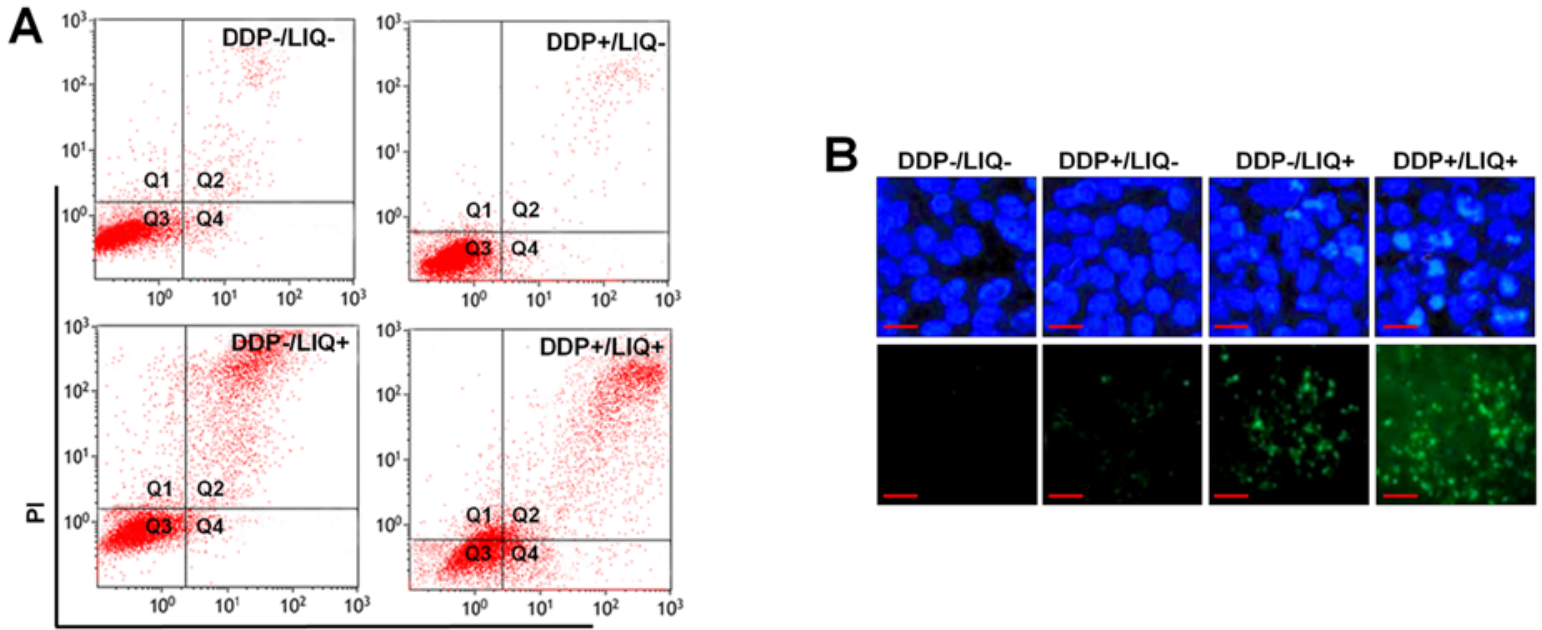

Annexin-V FITC
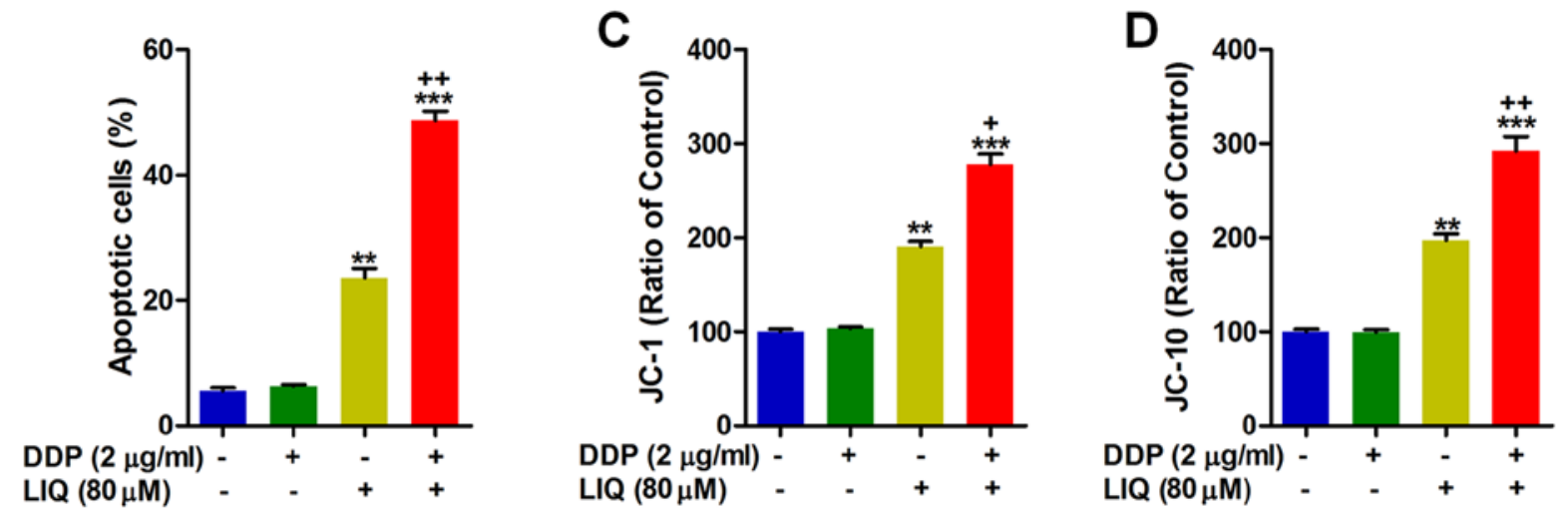

Figure 3. Liquiritin and DDP co-treatment enhances apoptosis in DDP-resistant gastric cancer cells. (A) SGC7901/DDP cells were cultured with DDP and LIQ or the two in combination for $24 \mathrm{~h}$. Then, all cells were harvested for apoptosis analysis using flow cytometry. The quantification of apoptotic cells is exhibited. (B) Hoechst 33258 staining (upper) and TUNEL staining (lower) were used to evaluate the apoptotic cells treated under different conditions. The mitochondrial membrane potential was verified through measuring (C) JC-1 and (D) JC-10 levels. Also, the ratio of control is shown. Data are presented as the mean $\pm \mathrm{SEM},{ }^{*} \mathrm{p}<0.05,{ }^{* *} \mathrm{p}<0.01$ and ${ }^{* * *} \mathrm{p}<0.001$ versus the DDP $/$ LIQ group. ${ }^{+} \mathrm{p}<0.05,{ }^{++} \mathrm{p}<0.01$ and ${ }^{+++} \mathrm{p}<0.001$ versus the $\mathrm{DDP}^{-} / \mathrm{LIQ}^{+}$group.

preventing tumor growth $(21,22)$. As shown in Fig. 5A, the TEM analysis indicated that the cell structure was severely damaged by LIQ treatment, which was accelerated due to its combination with DDP. Following, western blot analysis suggested that autophagy-related signals of LC3BI/II, and Beclin 1 were highly induced by LIQ single treatment, while p62 was found to be suppressed. Notably, DDP/LIQ co-treatment further augmented LC3BI/II and Beclin 1 expression and reduced p62 expression, resulting in autophagy in SGC7901/DDP cells (Fig. 5B). Finally, fluorescent analysis further evidenced that LC3B were highly induced by LIQ/DDP co-treatment compared to the $\mathrm{DDP}^{-} / \mathrm{LIQ}^{+}$group, indicating that autophagy could be induced by DDP/LIQ, resulting in gastric cancer cell death (Fig. 5C).

Liquiritin and DDP co-treatment suppresses tumor growth of xenograft mice in vivo. In vivo, the SGC7901/DDP cells $\left(2 \times 10^{5}\right)$ were subcutaneously inoculated into nude mice. When tumor size reached to $\sim 50 \mathrm{~mm}^{3}$, mice were randomly grouped to receive DDP (3 mg/kg) and LIQ $(15 \mathrm{mg} / \mathrm{kg}$ ) or the two in combination for 21 days. As shown in Fig. 6A and $\mathrm{B}$, we found that DDP and LIQ in combination significantly reduced the size, volume and weight of tumor compared to LIQ single treatment, suggesting that co-treatment of LIQ and DDP could reduce the growth of tumor in vivo. Fig. 6C also indicated that the number of tumor cells was obviously reduced by DDP and LIQ double therapy. Finally, the immunohistochemical analysis showed dramatically downregulated Ki-67 levels and upregulated TUNEL-positive cells in tumor tissue sections with DDP/LIQ treatment together, further indicating that DDP/LIQ impeded the tumor growth and induced apoptosis in vivo (Fig. 6D and E).

Liquiritin and DDP co-treatment induces apoptosis and autophagy in tumor tissues. The results above elucidated that DDP/LIQ co-treatment could trigger apoptosis and autophagy in vitro. Thus, here we attempted to explore if the possible molecular mechanism was involved in vivo. As shown in Fig. 7A and B, cleaved caspase-3- and LC3Bpositive cells were significantly elevated in DPP/LIQ-treated group of tumors. Furthermore, western blot analysis showed that high expression of cyclin D1 and CDK4 was reduced by LIQ, which were further downregulated by DDP/LIQ co-treatment. In contrast, p53 and p21 expressions were found to be markedly elevated in DDP/LIQ group, suggesting the suppressive effects of DDP/LIQ on gastric cancer growth (Fig. 7C). Also, the expression levels of cleaved caspase-8/9/-3 and PARP, contributing to the progression of apoptosis, 
A
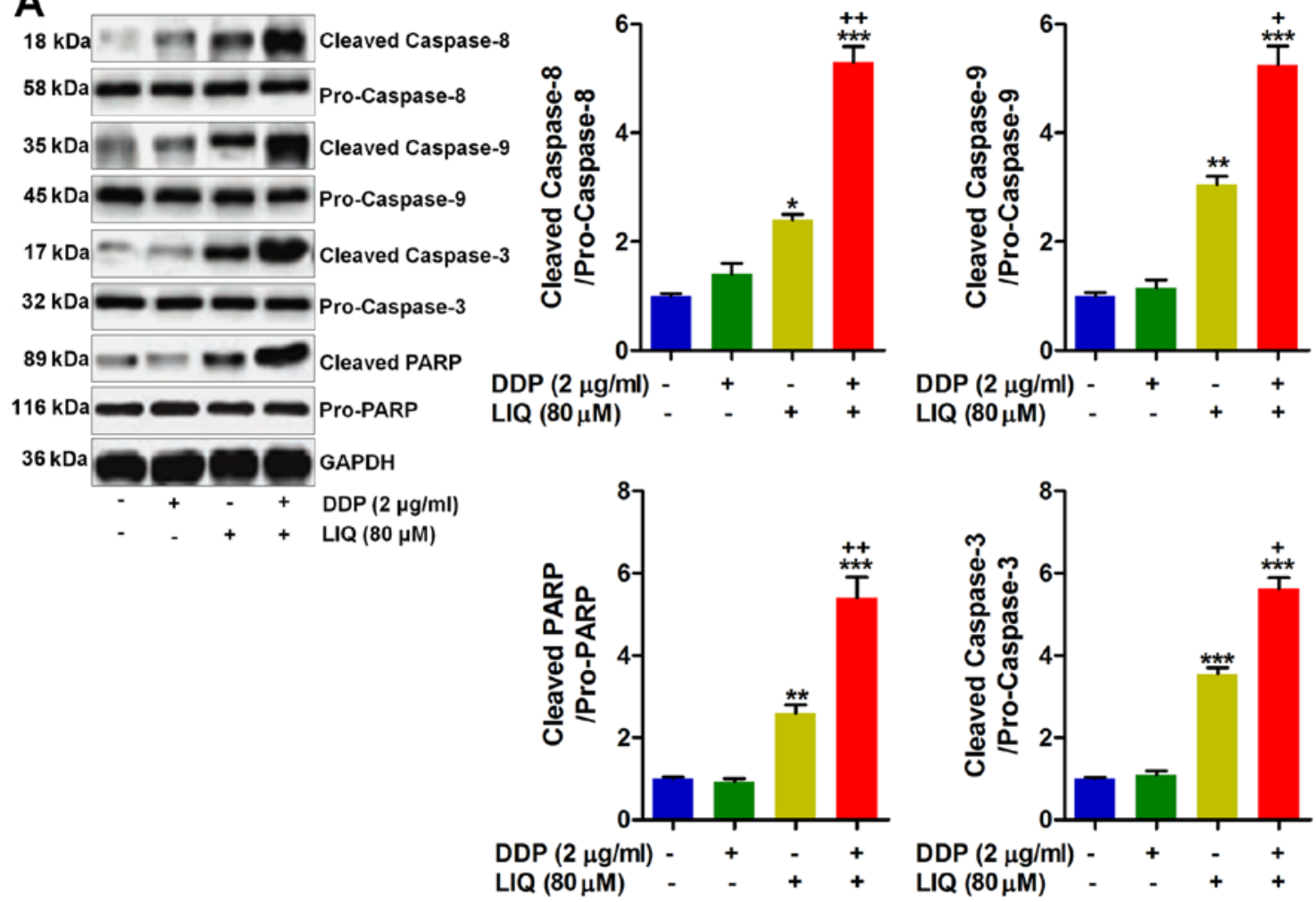

\section{B}
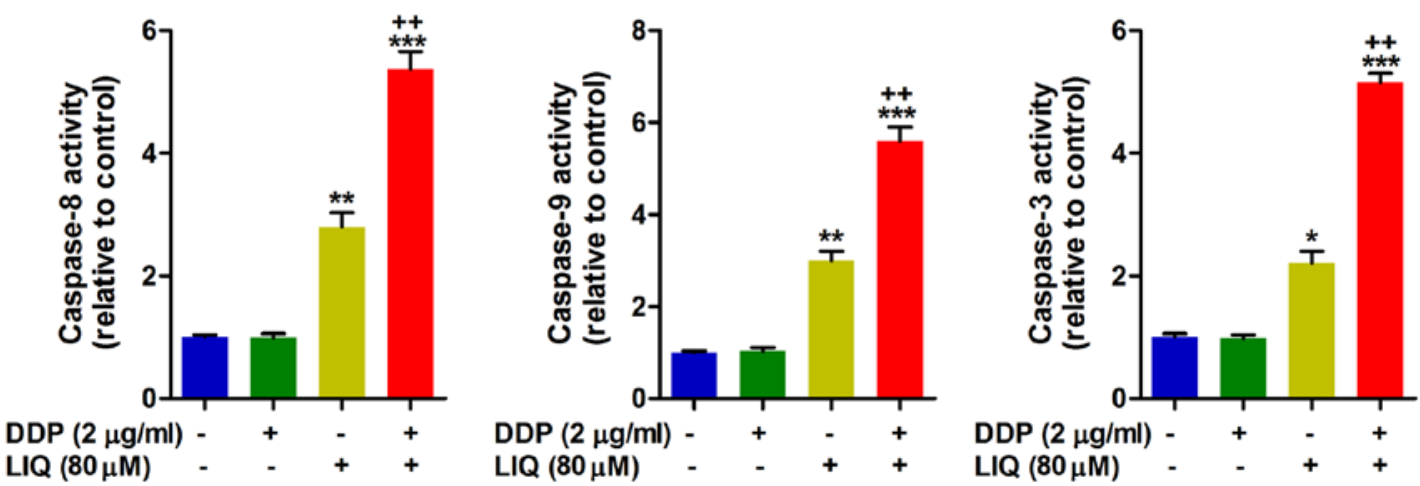

Figure 4. Caspase-3 signaling pathway is involved in liquiritin and DDP-induced apoptosis. (A) SGC7901/DDP cells were exposed to LIQ and DDP in single or double treatments for $24 \mathrm{~h}$, and then western blot analysis was performed to determine the expressions of cleaved caspase-8/-9/-3 and PARP. The quantification of each protein was displayed. In addition, the activity of active caspase-8/-9 and -3 was assessed $(\mathrm{B})$. Data are presented as the mean $\pm \mathrm{SEM},{ }^{*} \mathrm{p}<0.05,{ }^{* *} \mathrm{p}<0.01$ and ${ }^{* * *} \mathrm{p}<0.001$ versus the DDP $/$ LIQ $^{-}$group. ${ }^{+} \mathrm{p}<0.05,{ }^{++} \mathrm{p}<0.01$ and ${ }^{+++} \mathrm{p}<0.001$ versus the DDP $/ \mathrm{LIQ}^{+}$group.

were dramatically improved by co-treatment of DDP and LIQ (Fig. 7D). Also, autophagy-related molecules of LC3B and Beclin 1 were considerably induced by DDP/LIQ, while p62 was reduced, which were in line with the results in vitro (Fig. $7 \mathrm{E}$ ). In summary, the data above indicated that co-treatment of DDP/LIQ could induce apoptosis and autophagy in gastric tumor samples in vivo, performing its role in suppressing gastric tumor growth.

\section{Discussion}

During the process of tumor chemotherapy, one of the most intractable problems is the occurrence of drug resistance of cancer cells to chemotherapeutic drugs $(8,23,24)$. Resistance to chemotherapy is a major obstacle for the effective treatment of cancers. The mechanism of chemoresistance is still poorly understood. The development of multidrug resistance is a crucial problem of therapy failure in gastric cancer, which results in disease recurrence and metastasis $(25,26)$. In the clinical practice, a large number of Chinese medicine drugs have exhibited effective synergism in chemotherapy. The procedure has been evidenced in numerous studies $(27,28)$. Recently, liquiritin (LIQ) displayed comprehensive ability to prevent the progression of tumors, such as the non-small cell lung cancer (NSCLC) by inducing apoptosis (29). Though LIQ has been reported to have anticancer ability, how it suppressed cancer development and the underlying molecular mechanisms are not well known. Thus, further study is still required to fully explain its bioactivities against different types of cancer, including gastric carcinoma. Modern pharmacological studies have indicated that application of two drugs in combination could suppress the growth, prolifera- 

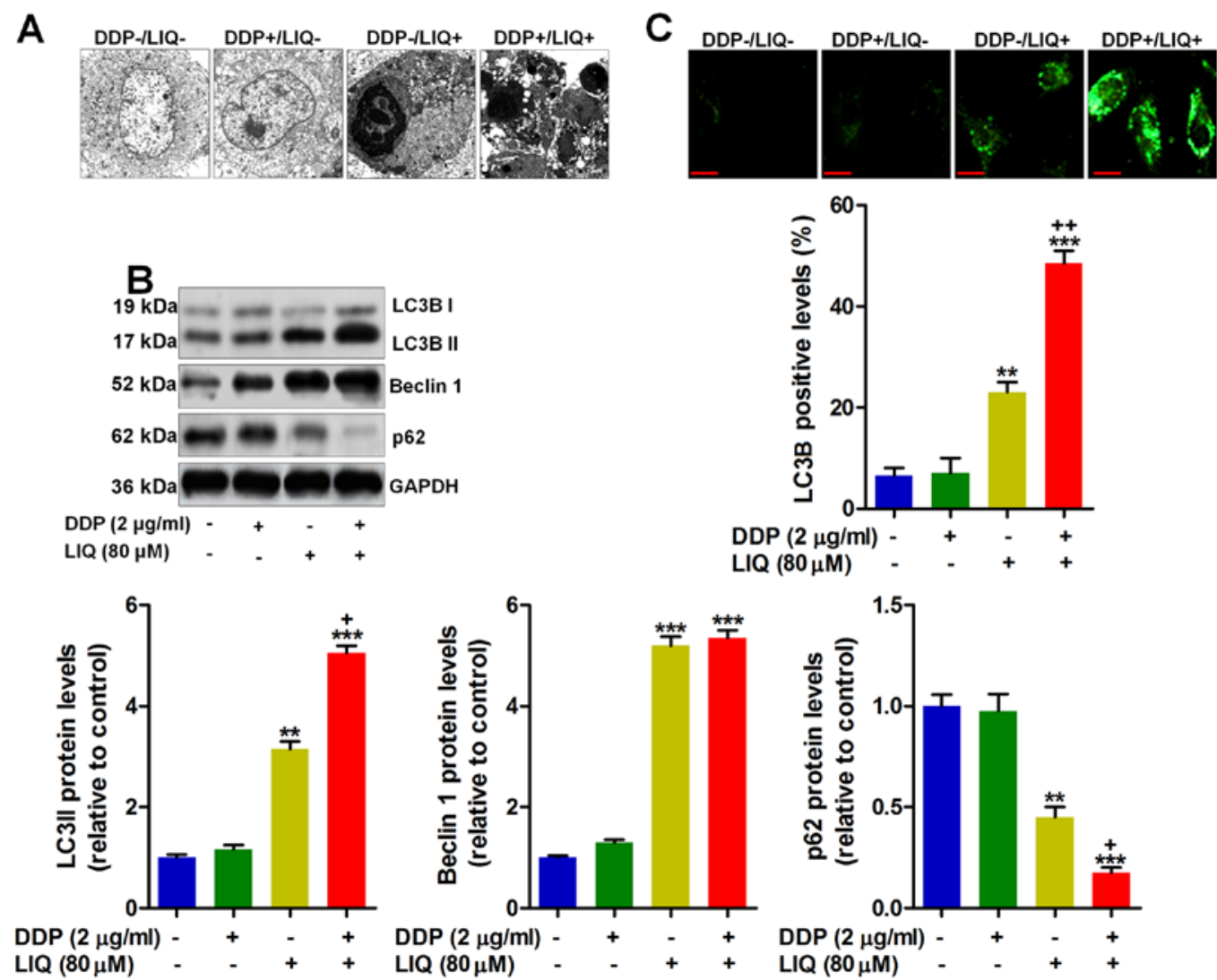

$\operatorname{DDP}(2 \mu \mathrm{g} / \mathrm{ml})$
$\operatorname{LIQ}(80 \mu \mathrm{M})$

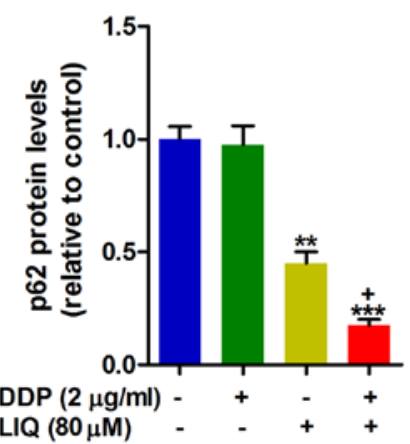

Figure 5. Liquiritin and DDP double therapy triggers autophagy in DDP-resistant gastric cancer cells. (A) The TEM study of SGC7901 treated as indicated. (B) Western blot analysis was used to determine autophagy-related signals, including LC3B, Beclin 1 and p62. The quantification of the proteins was exhibited following the immunoblotting analysis. (C) Immunofluorescent analysis was used to calculate LC3II levels in SGC7901/DDP cells. Data are presented as the mean \pm SEM, ${ }^{*} \mathrm{p}<0.05,{ }^{* *} \mathrm{p}<0.01$ and ${ }^{* * *} \mathrm{p}<0.001$ versus the DDP-LIQ group. ${ }^{+} \mathrm{p}<0.05,{ }^{++} \mathrm{p}<0.01$ and ${ }^{+++} \mathrm{p}<0.001$ versus the DDP $/ \mathrm{LIQ}^{+}$group.
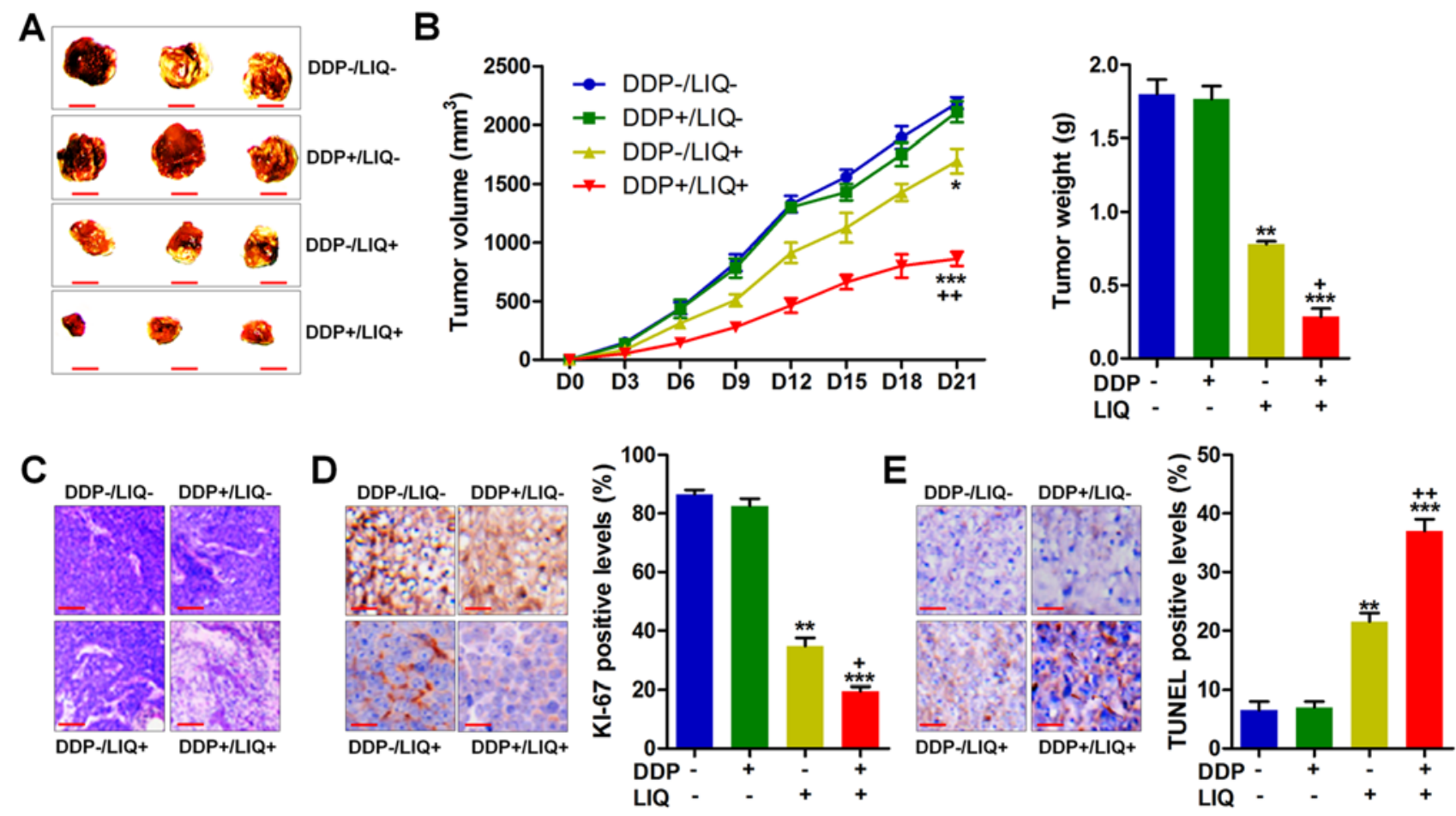

Figure 6. Liquiritin and DDP co-treatment suppresses tumor growth of xenograft mice in vivo. SGC7901/DDP cells (2x10 $\left.)^{5}\right)$ were subcutaneously inoculated into nude mice. When tumors were obvious (tumor size $\sim 50 \mathrm{~mm}^{3}$ ), mice were randomly grouped to receive DDP (3 $\mathrm{mg} / \mathrm{kg}$ ) and LIQ (15 mg/kg) or the two in combination for 21 days. (A) Representative images are displayed. (B) The tumor volume and weight were measured and the results are shown. (C) The H7E staining of tumor tissue samples from each group. (D) Ki-67 and (E) TUNEL levels expressed in tumors were measured using immunohistochemical analysis. Data are presented as the mean $\pm \mathrm{SEM},{ }^{*} \mathrm{p}<0.05,{ }^{* *} \mathrm{p}<0.01$ and ${ }^{* * *} \mathrm{p}<0.001$ versus the DDP $/$ LIQ group. ${ }^{+} \mathrm{p}<0.05,{ }^{++} \mathrm{p}<0.01$ and ${ }^{+++} \mathrm{p}<0.001$ versus the DDP $/ \mathrm{LIQ}^{+}$ group. 
A

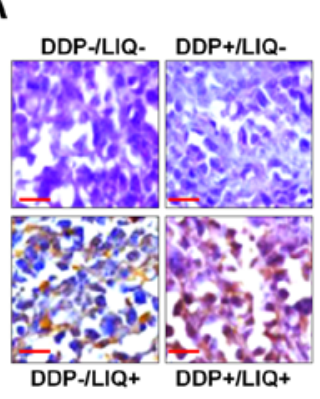

C

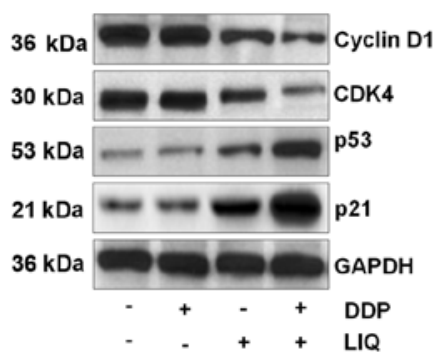

$\mathrm{D}$
$18 \mathrm{kDa}$
Cleaved Caspase-8 $18 \mathrm{kDa}$
$35 \mathrm{kDa}=-\mathrm{N}=\mathrm{Cleaved}$ Caspase-9 $17 \mathrm{kDa}=\mathrm{C}=\mathrm{Cleaved}$ Caspase-3 $89 \mathrm{kDa}=\mathrm{Cleaved}$ PARP $36 \mathrm{kDa} \longrightarrow$ GAPDH $+\quad+$ DDP LIQ

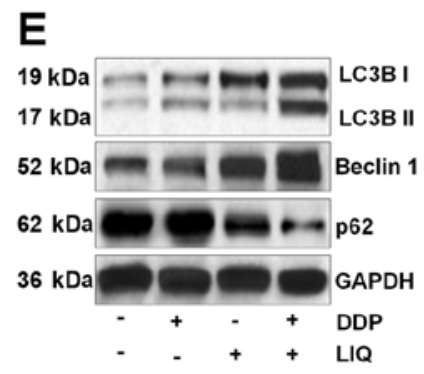

B

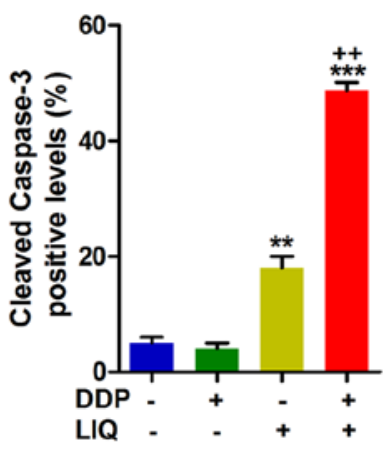

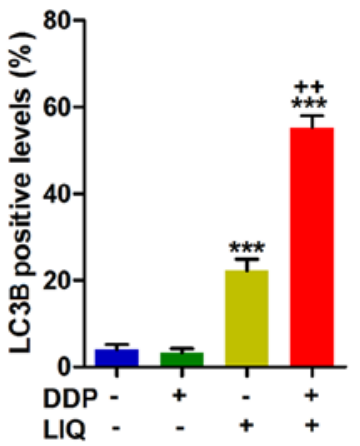
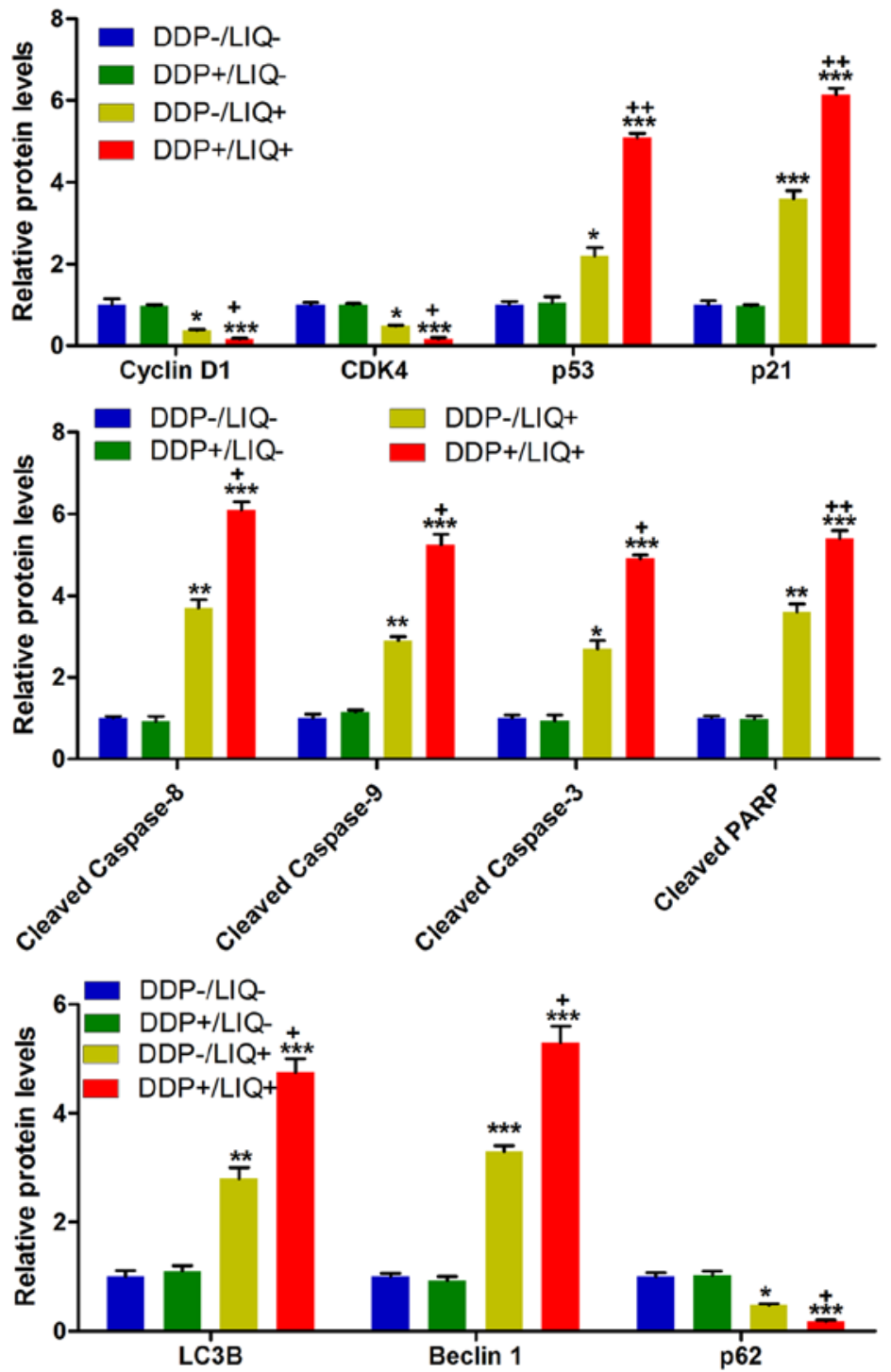

Figure 7. Liquiritin and DDP co-treatment induces apoptosis and autophagy in tumor tissues. (A) Cleaved caspase-3 and (B) LC3II expression levels were determined using immunohistochemical analysis. The percentage of cleaved caspase-3- and LC3II-positive levels is shown. (C) DNA damage checkpoint proteins were measured though western blot analysis. (D) Cleaved caspase-8/-9/-3 and cleaved PARP expression levels were tested using western blot analysis. (E) Autophagy-associated signals of LC3B, Beclin 1 and p62 were calculated through immunoblotting analysis. Data are represented as the mean \pm SEM, ${ }^{*} \mathrm{p}<0.05,{ }^{* *} \mathrm{p}<0.01$ and ${ }^{* * * *} \mathrm{p}<0.001$ versus the DDP $/$ LIQ $^{-}$group. ${ }^{+} \mathrm{p}<0.05,{ }^{++} \mathrm{p}<0.01$ and ${ }^{+++} \mathrm{p}<0.001$ versus the DDP $/ \mathrm{LIQ}^{+}$group.

tion, migration and invasion of various tumor cells, induce apoptosis and autophagy of tumor cells and impede the role of tumor-promoting substances on the potential tumor cells (30-32).

In order to further explore the role of LIQ in preventing gastric cancer, gastric cancer cells of SGC7901 with DDP resistance were used in our study. SGC7901/DDP cells show resistance to a large number of chemotherapeutic drugs $(33,34)$. We combined LIQ and DDP to prevent SGC7901/DDP cells. The results indicated that LIQ could enhance the killing ability of DDP on SGC7901/DDP cells and promote the effects of DDP on the induction of apoptosis and autophagy in SGC7901/DDP 
cells. Further, the cytotoxicity of LIQ was measured. MTT analysis indicated that there was no significant difference between the Con and LIQ-treated groups, indicating its safety for application within our conditions $(14,15)$. In vivo, LIQ and DDP in combination showed strongly suppressive effects on the growth of SGC7901/DDP xenograft tumor in nude mice. The results above suggested that LIQ could enhance the sensitivity of SGC7901/DDP cells to DDP treatment, reducing the drug resistance.

Cancer is characterized by abnormal cell growth, which evolves, at least partly by over-riding the regulation of cellular proliferation (35). Cyclins and cyclin-dependent kinases (CDKs) are tightly included in the process of cell cycle in tumor cells. CDKs are important modulators of cell cycle machinery, influencing the progression of cell cycle from one phase to the next $(36,37)$. Unusual cyclins and CDK activity leads to dysregulation of programmed cell death or apoptotic development, which contributes to selective growth advantage for tumor cells. Dys-regulated cell cycle process is an essential factor during development and progression of cancer $(38,39)$. Controlling the process of cell cycle in tumor cells is an effective therapeutic strategy to inhibit tumor growth and development, and cell cycle regulators are deregulated in most common malignancies $(40,41)$. Regulating the cell cycle at G1 checkpoint is complex, including multiple molecular processes. P53 is a frequent target for mutation in various human tumors (42). Additionally, p53 could respond to different stresses, such as the cell cycle arrest, DNA repair, and apoptosis (43). As reported previously, p21 plays an essential role in diminishing the G1 cell cycle arrest in different tumor cells. P53 inhibits the cell cycle progression by triggering CDK suppressors, including p21 (44). In our study, we found that G1/G0 cell cycle arrest was induced by LIQ, which was further enhanced by LIQ and DDP in combination. Also, consistently, cyclin D1, cyclin A and CDK4 were highly induced by LIQ/DDP co-treatment, while p53 and p 21 were reduced, indicating that LIQ potentiated the effects of DDP on the suppression of SGC7901/DDP cells.

Apoptosis is a morphologically obvious form of programmed cell death, which plays an essential role in regulating homeostasis and development of organisms. In addition, the progression of numerous diseases is linked with apoptosis, including different cancers $(45,46)$. Inducing apoptosis is an important molecular mechanism by which a variety of anticancer drugs were explored (47). In our present study, we found that apoptosis was highly induced by LIQ and DDP co-treatment through flow cytometry, Hoechst 33258 and TUNEL staining. Caspase is a family of cysteine proteases, modulating apoptosis (48). In response to cell death stimuli, Bax could migrate to mitochondria to induce a cascade of mitochondrial permeability transition pore-related events, resulting in a downregulation in the mitochondrial membrane potential and apoptosis (49). In the end, caspase-9 is activated, promoting the cleavage of caspase-3 and PARP, which contributes to apoptosis and ultimately cell death (50). Caspase- 8 participates in the extrinsic apoptosis signaling, which is another mechanism to induce apoptosis (51). In our study, we found that cleaved caspase-8/-9/-3 and PARP were expressed highly in the group of LIQ/DDP, revealing that LIQ might enhance the role of DDP in inducing apoptosis in SGC7901/DDP cells, dependent on both intrinsic and extrinsic signaling pathways.
Autophagy is a homeostatic and catabolic process, which is crucial for the packaging and degradation of cytoplasmic proteins and organelles (52). Therefore, autophagy is necessary to maintain genomic stability and overall cell survival (21). Microtubule-associated protein light chain 3 (LC3) is localized and accumulated on the autophagosome, which is well known as an important hallmark of autophagy (53). LC3B transforms from LC3B-I to LC3B-II, resulting in autophagosome formation (54). Beclin 1 is another important marker of autophagy. Beclin 1 forms a complex with type III phosphatidylinositol that allows the nucleation of the autophagic vesicles (55). p62 has a close relationship with autophagy, possessing an LC3-interacting region (56). In our study, LIQ improved the effects of DPP to trigger autophagy in SGC7901/DDP cells, evidenced by the considerable increasing of LC3B, Beclin 1 and decreasing of p62. In the present study in vivo, we found that LIQ/DDP co-treatment significantly downregulated the SGC7901/DDP tumor growth, proved by limited tumor volume and tumor weight. Furthermore, the western blot and histochemistry analysis further ensured the suppression of cyclin D1 and CDK4, improvement of p53, p21, cleaved caspase-8/-9/-3 and PARP, as well as elevation of LC3B-II and Beclin 1 after treatment of LIQ/DDP in animals, indicating that LIQ might be effective in blunting tumor growth and inducing apoptosis and autophagy.

In conclusion, the results above indicated that LIQ could enhance the pro-apoptotic effect of DDP on human gastric cancer SGC7901/DDP cells through arresting G0/G1 phase cycle, inducing apoptosis and autophagy. In the xenograft models, LIQ/ DDP administration showed obvious anticancer activity with reduced tumor volume and weight. Thus, LIQ could be considered as synergistic drug with DDP to prevent gastric cancer.

\section{Acknowledgements}

This study was supported by the Science and Technology Planning Project: 'The relationship between difference of different stem cell subsets and prognosis in liver metastasis of colorectal cancer', Jilin, P.R. China (20170414034GH).

\section{References}

1. Kamangar F, Dores GM and Anderson WF: Patterns of cancer incidence, mortality, and prevalence across five continents: Defining priorities to reduce cancer disparities in different geographic regions of the world. J Clin Oncol 24: 2137-2150, 2006.

2. Torre LA, Bray F, Siegel RL, Ferlay J, Lortet-Tieulent J and Jemal A: Global cancer statistics, 2012. CA Cancer J Clin 65: 87-108, 2015.

3. Sakuramoto S, Sasako M, Yamaguchi T, Kinoshita T, Fujii M, Nashimoto A, Furukawa H, Nakajima T, Ohashi Y, Imamura H, et al; ACTS-GC Group: Adjuvant chemotherapy for gastric cancer with S-1, an oral fluoropyrimidine. N Engl J Med 357: 1810-1820, 2007.

4. Brambilla G and Martelli A: Genotoxic and carcinogenic risk to humans of drug-nitrite interaction products. Mutat Res 635: 17-52, 2007.

5. Van Cutsem E, Moiseyenko VM, Tjulandin S, Majlis A, Constenla M, Boni C, Rodrigues A, Fodor M, Chao Y, Voznyi E, et al; V325 Study Group: Phase III study of docetaxel and cisplatin plus fluorouracil compared with cisplatin and fluorouracil as first-line therapy for advanced gastric cancer: A report of the V325 Study Group. J Clin Oncol 24: 4991-4997, 2006.

6. Tsutani Y, Yoshida K, Sanada Y, Wada Y, Konishi K, Fukushima M and Okada M: Decreased orotate phosphoribosyltransferase activity produces 5 -fluorouracil resistance in a human gastric cancer cell line. Oncol Rep 20: 1545-1551, 2008. 
7. Zheng LH, Bao YL, Wu Y, Yu CL, Meng X and Li YX: Cantharidin reverses multidrug resistance of human hepatoma HepG2/ADM cells via down-regulation of P-glycoprotein expression. Cancer Lett 272: 102-109, 2008.

8. Kang YK, Kang WK, Shin DB, Chen J, Xiong J, Wang J, Lichinitser M, Guan Z, Khasanov R, Zheng L, et al: Capecitabine/ cisplatin versus 5 -fluorouracil/cisplatin as first-line therapy in patients with advanced gastric cancer: A randomised phase III noninferiority trial. Ann Oncol 20: 666-673, 2009.

9. Rennicke A, Voigt W, Mueller T, Fruehauf A, Schmoll HJ, Beyer C and Dempke W: Resistance mechanisms following cisplatin and oxaliplatin treatment of the human teratocarcinoma cell line 2102EP. Anticancer Res 25A: 1147-1155, 2005.

10. Tian ML, Yan HY and Row KH: Simultaneous extraction and separation of liquiritin, glycyrrhizic acid, and glabridin from licorice root with analytical and preparative chromatography. Biotechnol Bioprocess Eng; BBE 13: 671-676, 2008.

11. Lee JY, Lee JH, Park JH, Kim SY, Choi JY, Lee SH, Kim YS, Kang SS, Jang EC and Han Y: Liquiritigenin, a licorice flavonoid, helps mice resist disseminated candidiasis due to Candida albicans by Th1 immune response, whereas liquiritin, its glycoside form, does not. Int Immunopharmacol 9: 632-638, 2009.

12. Wang W, Hu X, Zhao Z, Liu P, Hu Y, Zhou J, Zhou D, Wang Z, Guo D and Guo H: Antidepressant-like effects of liquiritin and isoliquiritin from Glycyrrhiza uralensis in the forced swimming test and tail suspension test in mice. Prog Neuropsychopharmacol Biol Psychiatry 32: 1179-1184, 2008.

13. Dong S, Inoue A, Zhu Y, Tanji M and Kiyama R: Activation of rapid signaling pathways and the subsequent transcriptional regulation for the proliferation of breast cancer MCF-7 cells by the treatment with an extract of Glycyrrhiza glabra root. Food Chem Toxicol 45: 2470-2478, 2007.

14. Aboue A and Al-Shawi AAA: Liquiritin (LG), isolated and identified from Radix Glycyrrhizae (RG), inhibits the proliferation and induces apoptosis of human gastric cancer cells (MGC-803). Int J Curr Microbiol Appl Sci 3: 89-98, 2014

15. Gao YX, Cheng BF, Lian JJ, Guo D-D, Qin J-W, Zhang Y-B, Yang H-J, Wang M, Wang $L$ and Feng Z-W: Liquiritin, a flavone compound from licorice, inhibits IL-1 $\beta$-induced inflammatory responses in SW982 human synovial cells. J Funct Foods 33: 142-148, 2017.

16. Selvakumaran M, Pisarcik DA, Bao R, Yeung AT and Hamilton TC: Enhanced cisplatin cytotoxicity by disturbing the nucleotide excision repair pathway in ovarian cancer cell lines. Cancer Res 63: 1311-1316, 2003.

17. Kim YW, Ki SH, Lee JR, Lee SJ, Kim CW, Kim SC and Kim SG Liquiritigenin, an aglycone of liquiritin in Glycyrrhizae radix, prevents acute liver injuries in rats induced by acetaminophen with or without buthionine sulfoximine. Chem Biol Interact 161: 125-138, 2006.

18. Vanella L, Di Giacomo C, Acquaviva R, Barbagallo I, Cardile V, Kim DH, Abraham NG and Sorrenti V: Apoptotic markers in a prostate cancer cell line: Effect of ellagic acid. Oncol Rep 30: 2804-2810, 2013

19. Yang XH, Zheng X, Cao JG, Xiang HL, Liu F and Lv Y: 8-Bromo-7-methoxychrysin-induced apoptosis of hepatocellular carcinoma cells involves ROS and JNK. World J Gastroenterol 16: 3385-3393, 2010

20. Gyrd-Hansen M and Meier P: IAPs: From caspase inhibitors to modulators of NF-kappaB, inflammation and cancer. Nat Rev Cancer 10: 561-574, 2010.

21. Yang ZJ, Chee CE, Huang S and Sinicrope F: Autophagy modulation for cancer therapy. Cancer Biol Ther 11: 169-176, 2011

22. Zhai B, Hu F, Jiang X, Xu J, Zhao D, Liu B, Pan S, Dong X, Tan G, Wei Z, et al: Inhibition of Akt reverses the acquired resistance to sorafenib by switching protective autophagy to autophagic cell death in hepatocellular carcinoma. Mol Cancer Ther 13: 1589-1598, 2014

23. Zhao D, Jiang Y, Dong X, Liu Z, Qu B, Zhang Y, Ma N and Han Q: Arsenic trioxide reduces drug resistance to adriamycin in leukemic K562/A02 cells via multiple mechanisms. Biomed Pharmacother 65: 354-358, 2011.

24. Zhao Y, You H, Liu F, An H, Shi Y, Yu Q and Fan D: Differentially expressed gene profiles between multidrug resistant gastric adenocarcinoma cells and their parental cells. Cancer Lett 185 211-218, 2002

25. Zhang XW, Bu P, Liu L, Zhang XZ and Li J: Overexpression of long non-coding RNA PVT1 in gastric cancer cells promotes the development of multidrug resistance. Biochem Biophys Res Commun 462: 227-232, 2015.
26. Huang S, Chen M, Shen Y, Shen W, Guo H, Gao Q and Zou X: Inhibition of activated Stat3 reverses drug resistance to chemotherapeutic agents in gastric cancer cells. Cancer Lett 315: 198-205, 2012.

27. Ganta S and Amiji M: Coadministration of Paclitaxel and curcumin in nanoemulsion formulations to overcome multidrug resistance in tumor cells. Mol Pharm 6: 928-939, 2009.

28. Kim MK, Choi HS, Cho SG, Shin YC and Ko SG: Rubus coreanus Miquel extract causes apoptosis of doxorubicin-resistant NCI/ ADR-RES ovarian cancer cells via JNK phosphorylation. Mol Med Rep 13: 4065-4072, 2016.

29. Zhou Y and Ho WS: Combination of liquiritin, isoliquiritin and isoliquirigenin induce apoptotic cell death through upregulating p53 and p21 in the A549 non-small cell lung cancer cells. Oncol Rep 31: 298-304, 2014.

30. Matsumoto $\mathrm{H}$, Inaba $\mathrm{H}$, Kishi $\mathbf{M}$, Tominaga S, Hirayama $\mathbf{M}$ and Tsuda T: Orally administered delphinidin 3-rutinoside and cyanidin 3-rutinoside are directly absorbed in rats and humans and appear in the blood as the intact forms. J Agric Food Chem 49: 1546-1551, 2001

31. Hagiwara Y, Kasukabe T, Kaneko Y, Niitsu N and Okabe-Kado J: Ellagic acid, a natural polyphenolic compound, induces apoptosis and potentiates retinoic acid-induced differentiation of human leukemia HL-60 cells. Int J Hematol 92: 136-143, 2010.

32. Yang ZC and Ma J: Actein enhances TRAIL effects on suppressing gastric cancer progression by activating $\mathrm{p} 53 /$ Caspase-3 signaling. Biochem Biophys Res Commun: Nov 30, 2016 (Epub ahead of print). doi: 10.1016/j.bbrc.2016.11.162.

33. Kumar A, Wessels D, Daniels KJ, Alexander H, Alexander S and Soll DR: Sphingosine-1-phosphate plays a role in the suppression of lateral pseudopod formation during Dictyostelium discoideum cell migration and chemotaxis. Cell Motil Cytoskeleton 59: 227-241, 2004

34. Li G, Yang F, Gu S, Li Z and Xue M: MicroRNA-101 induces apoptosis in cisplatin-resistant gastric cancer cells by targeting VEGF-C. Mol Med Rep 13: 572-578, 2016.

35. Schwartz GK and Shah MA: Targeting the cell cycle: A new approach to cancer therapy. J Clin Oncol 23: 9408-9421, 2005.

36. Aggarwal P, Vaites LP, Kim JK, Mellert H, Gurung B, Nakagawa H, Herlyn M, Hua X, Rustgi AK, McMahon SB, et al: Nuclear cyclin D1/CDK4 kinase regulates CUL4 expression and triggers neoplastic growth via activation of the PRMT5 methyltransferase. Cancer Cell 18: 329-340, 2010.

37. Bockstaele L, Bisteau X, Paternot S and Roger PP: Differential regulation of cyclin-dependent kinase 4 (CDK4) and CDK6, evidence that CDK4 might not be activated by CDK7, and design of a CDK6 activating mutation. Mol Cell Biol 29: 4188-4200, 2009.

38. Perisanidis C, Perisanidis B, Wrba F, Brandstetter A, El Gazzar S, Papadogeorgakis N, Seemann R, Ewers R, Kyzas PA and Filipits M: Evaluation of immunohistochemical expression of p53, p21, p27, cyclin D1, and Ki67 in oral and oropharyngeal squamous cell carcinoma. J Oral Pathol Med 41: 40-46, 2012

39. Kim YA, Lee WH, Choi TH, Rhee SH, Park KY and Choi YH: Involvement of p21WAF1/CIP1, pRB, Bax and NF-kappaB in induction of growth arrest and apoptosis by resveratrol in human lung carcinoma A549 cells. Int J Oncol 23: 1143-1149, 2003.

40. Liu P, Wang X, Hu C and $\mathrm{Hu} \mathrm{T}$ : Inhibition of proliferation and induction of apoptosis by trimethoxyl stilbene (TMS) in a lung cancer cell line. Asian Pac J Cancer Prev 12: 2263-2269, 2011.

41. Le NT and Richardson DR: The role of iron in cell cycle progression and the proliferation of neoplastic cells. Biochim Biophys Acta 1603: 31-46, 2002.

42. Alao JP: The regulation of cyclin D1 degradation: Roles in cancer development and the potential for therapeutic invention. Mol Cancer 6: 24, 2007.

43. Horn HF and Vousden KH: Coping with stress: Multiple ways to activate p53. Oncogene 26: 1306-1316, 2007.

44. Chatterjee SJ, Datar R, Youssefzadeh D, George B, Goebell PJ, Stein JP, Young L, Shi SR, Gee C, Groshen S, et al: Combined effects of $\mathrm{p} 53, \mathrm{p} 21$, and $\mathrm{pRb}$ expression in the progression of bladder transitional cell carcinoma. J Clin Oncol 22: 1007-1013, 2004.

45. Chen MB, Wu XY, Gu JH, Guo QT, Shen WX and Lu PH: Activation of AMP-activated protein kinase contributes to doxorubicin-induced cell death and apoptosis in cultured myocardial H9c2 cells. Cell Biochem Biophys 60: 311-322, 2011.

46. Circu ML and Aw TY: Glutathione and modulation of cell apoptosis. Biochim Biophys Acta 1823: 1767-1777, 2012. 
47. Andersen JL and Kornbluth S: The tangled circuitry of metabolism and apoptosis. Mol Cell 49: 399-410, 2013.

48. Suzuki Y, Nakabayashi Y, Nakata K, Reed JC and Takahashi R: X-linked inhibitor of apoptosis protein (XIAP) inhibits caspase-3 and -7 in distinct modes. J Biol Chem 276: 27058-27063, 2001.

49. Xiong Y, Lu QJ, Zhao J and Wu GY: Metformin inhibits growth of hepatocellular carcinoma cells by inducing apoptosis via mitochondrion-mediated pathway. Asian Pac J Cancer Prev 13: 3275-3279, 2012

50. Hasan TN, B LG, Shafi G, Al-Hazzani AA and Alshatwi AA: Anti-proliferative effects of organic extracts from root bark of Juglans Regia L. (RBJR) on MDA-MB-231 human breast cancer cells: Role of Bcl-2/Bax, caspases and Tp53. Asian Pac J Cancer Prev 12: 525-530, 2011.

51. Sträter J, Herter I, Merkel G, Hinz U, Weitz J and Möller P: Expression and prognostic significance of APAF-1, caspase-8 and caspase-9 in stage II/III colon carcinoma: Caspase- 8 and caspase-9 is associated with poor prognosis. Int J Cancer 127: $873-880,2010$
52. Schleicher SM, Moretti L, Varki V and Lu B: Progress in the unraveling of the endoplasmic reticulum stress/autophagy pathway and cancer: Implications for future therapeutic approaches. Drug Resist Updat 13: 79-86, 2010.

53. Chen ZH, Lam HC, Jin Y, Kim HP, Cao J, Lee SJ, Ifedigbo E, Parameswaran H, Ryter SW and Choi AM: Autophagy protein microtubule-associated protein 1 light chain-3B (LC3B) activates extrinsic apoptosis during cigarette smoke-induced emphysema. Proc Natl Acad Sci USA 107: 18880-18885, 2010.

54. Klionsky DJ, Abeliovich H, Agostinis P, Agrawal DK, Aliev G, Askew DS, Baba M, Baehrecke EH, Bahr BA, Ballabio A, et al: Guidelines for the use and interpretation of assays for monitoring autophagy in higher eukaryotes. Autophagy 4: 151-175, 2008

55. Yue Z, Jin S, Yang C, Levine AJ and Heintz N: Beclin 1, an autophagy gene essential for early embryonic development, is a haploinsufficient tumor suppressor. Proc Natl Acad Sci USA 100: 15077-15082, 2003.

56. Mizushima N and Yoshimori T: How to interpret LC3 immunoblotting. Autophagy 3: 542-545, 2007. 